\title{
SHATTERING SILENCE: TRACING SPECIESISM IN PHILIPPINE CHILDREN'S LITERATURE
}

\author{
Chryssa Celestino \\ Hinge Inquirer Publications \\ chryssaac@yahoo.com \\ ccelestino@hip.ph
}

\begin{abstract}
What does it mean to write the animal? In Philippine children's literature where the population of the nonhuman animal is difficult to ignore, writing (about) them is supposed to aspire familiarization: an action that guides the child reader toward concepts of animality. The nonhuman animal has also been recognized as therapeutic narrative elements, aids in identity construction, and effective fictional teachers of species relationships. The inclusion and, more accurately, the functions of the nonhuman animal in the text, however, are symptomatic of speciesism: the belief in human superiority, and the redundant establishment of their supremacy. Influenced by the insights of the likes of Jacques Derrida, Tony Milligan, Tom Regan and the plights of the "animal turn," this paper exposes the speciesist and marginalizing misrepresentation of nonhuman animals in both word and visuals that exist in select children's picture books. Both sides of the binary-the human/ nonhuman animal-are significant elements in the discussion; to talk about one side entails remembering the other. Hence, an exploration of representation yields conclusions about the literary, and perhaps even the real, relationship between the two. The dangers these misrepresentations and conclusions pose to the mindset of children not only prove threatening to nonhuman animals, but also to the construct of equal significance among species.
\end{abstract}

\section{Keywords}

Human-animal studies, Philippine fiction, distanced approach, intrinsic value, inherent value

\begin{abstract}
About the Author
Chryssa Celestino graduated Magna Cum Laude with a bachelor's degree in Literature at De La Salle University in 2013. The present article is derived from her undergraduate thesis "Approaching the Animot: Human-Animal Representations, Limits, and Relationships in Philippine Children's Literature," which problematizes the anthropocentric approach of Philippine children's narratives to the nonhuman animal. Her thesis won the Outstanding Thesis Award. She is currently an assistant editor for community magazines at Hinge Inquirer Publications. Prior to working, she has served internships and written for commercial publications.
\end{abstract}


"The animal is there before me, there close to me, there in front of me-I who am (following) after it. And also, therefore, since it is before me, it is behind me. It surrounds me."

Jacques Derrida 1

Where is the animal? The animal is the black cat that crossed the road, and the alligator on the pastel-colored cotton shirts; it is the fried chicken sitting on today's lunch plate and the big, yellow bird entertaining in Sesame Street on Saturday mornings. The animal is here, and just about everywhere; its lingering existence is a consequence of its natural parallelism to the human animal-a parallelism further characterized by referentiality, coexistence, and hunting (Derrida 380). Both species are referential. As a binary, it demands it. Coexistence is a reality where these "organisms only exist insofar as they coexist" (Cohen, "Human Tendencies"). And in their coexistence, these species have been in pursuit of each other for either concrete or abstract needs. The dualistic reality of the human/nonhuman animal suggests that both "have equal importance and it is immoral to pretend or act differently" (qtd. in Tester 12).

In this essay asserting that both human and nonhuman animal have equal importance-which also takes the form of the synonym "equal significance" in this paper-means to posit that both have worth as ends-in-themselves in as much as both are "deserving of the concern and consideration of all moral agents" (Taylor 201). ${ }^{2}$ To argue, then, that the nonhuman animal in Philippine children's literature is employed merely as an instrument that owes its value to its human use and circumstance; is to expose the genre of its plausible ties to speciesism, "the endorsement of (or action in line with) any belief whatsoever that is normatively equivalent to regarding humans as the only creaturely bearers of value or as creatures whose value as humans systematically trumps the value of all other creatures" (Milligan 226). ${ }^{3}$

\section{THE NONHUMAN ANIMAL IN PHILIPPINE CHILDREN'S LITERATURE}

Philippine children's literature follows the nonhuman animal in that the former practices the human tendency of approaching by incorporating the species into the written word.

The approach is significant: lending presence to the nonhuman animal is critical to the genre's primary objective of familiarizing children with animals by "provid[ing] material that will enhance a child's understanding of [them], of nature, of the world, and of the child's place in that world" (Bekoff 1031). From the precolonial times to the early post-war years, for instance, nonhuman animals have become characters that help in transmitting values and concepts to children. Local folktales, particularly fables, like the "The Horse and the Carabao," and trickster 
tales, such as those of Pelanduk, are among the earliest children's narratives that incorporate nonhuman animals for social, didactic purposes (Eugenio 161).

\section{FUNCTIONS OF THE NONHUMAN ANIMAL}

But the nonhuman animal is also significant in itself. Its significance rests on its mostly psychological functions in the genre. The nonhuman animal has secured its place in children's literature as a psychological aid for children coping with difficult situations. Carolyn Burke and Joby Copenhaver note that anthropomorphizing nonhuman animals can "add emotional distance for the reader when the story's message [becomes] powerful or painful" (205). Emotional distance is created by "soften[ing] the didactic tone" and "having animals do the acting and mistakemaking" which allows the child to "join the conversation" (213). Nonhuman animals prove to be effective, therapeutic entities that help forward distant yet easier problem-solving by encouraging evaluation of one's own possible approach to and action in particular circumstances.

The nonhuman animal also serves as a crucial character that aids in the child's construction of his/her personal and human ${ }^{4}$ self. Children share an affinity with the nonhuman animal. Either the reason is their attraction to living things or their animist nature ${ }^{5}$ children are more at ease to explore identities with the nonhuman animal because they do not feel intimidated by them (Bekoff 205). Nonhuman animals make perfect audiences to which children can perform or try out identities. Children feel comfortable in being seen by the nonhuman animal, and relaxed when the latter helps in the identity construction of the protagonists they read about. Nonhuman animals in literature help children understand who they are, as person and human, in the face of animality.

The inclusion of the nonhuman animal is also believed to be beneficial to the nonhuman animal species because it guides the human reader to proper, benevolent ways of approaching and even taming them. Children's human/nonhuman animal books effectively help teach kind nonhuman animal treatment (Rivera, "Teaching Kids Kindness to Animals"). Usually, these "animal stories [contain] a moral point, a lesson about the limits to kindness," about the proper approach to "animal otherness" (Webb 95). Apart from introducing animality, these particular animal narratives, with both humans/nonhuman animals, may introduce ways of approaching it through storylines and illustrations that suggest how the relationship may take place.

It is impossible to overlook the population of nonhuman animals in Philippine children's literature. However, the nature of their overwhelming presence here is that of a paradox, a presence marked by an absence of appropriate representation. 
The nonhuman animal's functions-helping the child cope with difficult situations, develop him/herself, and be reminded of proper treatment of animals-are notably "[humanist] to the core," with all of its functions rooted in human concerns (Wolfe 1). The nonhuman animal is reduced into a tool by its first and second functions, and into a creature to be subjugated by its third function. All the nonhuman animal becomes is an entity significant only when it caters to the human. The nonhuman animal, despite its overt presence in children's narratives, is obscured by the inferiority and passivity attributed to it-so lacking of agency for a species as significant as humans.

These tendencies observed can be as speciesist as they come, yielding questionable and marginalizing depictions of the nonhuman animal in select local children's texts. These representations consequently pose challenges to the literary genre that seeks to educate the young about animality.

Imparting the consequences of some of these speciesist practices on the perception of the human/nonhuman animal is a means of contributing to the young field of human-animal studies in the local setting. The method to be employed is a form of chasing: a going after the silenced nonhuman animal to examine its plight. The examination, however, requires analysis of both human/nonhuman animal, particularly their limits, representations, and relationships in the narratives. The natural interconnectedness of both species contributes to the impossibility of tackling only one species. Hence, the examination of the nonhuman animal may also yield insights on its human counterpart. This paper ends with the discussion of the implications of the analysis to the genre's social functions.

Six contemporary local children's picture books will be used to represent the genre: Lakambini Sitoy's “The Night Monkeys,” Nikki Alfar's “Menggay's Magical Chicken," Natasha Vizcarra's Ang Itim na Kuting (The Black Kitten), Annette Flores Garcia's The Tiger on the Wall, Becky Bravo's The Cat Painter, and Fetch.

Apart from contributing to the diversity of Philippine children's literature, these authors have made their mark on the local and global literary scene with their respective fiction. Multi-award winner Lakambini Sitoy has released two local collections of short stories and a novel, all while getting published across the US, UK and Europe ("Lakambini Sitoy"). Nikki Alfar pens the fantastic in more ways than one: as author of the short story collection Now, Then and Elsewhere, as contributor to local and international literary publications, and as co-editor of the annual anthology series Philippine Speculative Fiction ("Nikki Alfar"). Annette Flores Garcia, Natasha Vizcarra and Becky Bravo are distinguished for their brand of children's stories and have been published more than once by premier local houses such as Adarna House and Tahanan.

As mentioned, these texts are appropriate for children ages seven to 11. Due to their "stories being complex [wherein] subplots involving secondary characters are woven in the story, and themes [are] more sophisticated," "The Night Monkeys" 
and Fetch, however, are targeted toward more mature readers, ranging from ages eight to 12 (Backes, "Understanding Children's Book Genres”).

These works are chosen as a way of sampling literary children's texts with varying nonhuman animal species, and thus; magnifying an apparent speciesist symptom unique to them: the nonhuman animal character is made to seem important by fulfilling a role and achieving literary relevance through humans. Its purpose in the text is devoid of implications about their unique role as a nonhuman animal. Their roles do not always revolve around human animals insofar as their ecological functions can be independent from the latter, since they are species that reign over their respective habitats and spaces too.

\section{HUMAN/NONHUMAN ANIMAL LIMITS}

The question of speciesism may only be raised when two conditions exist. One is when the genre displays an awareness of the notion of species; and the second is when the genre makes an effort to differentiate species from one another. These conditions manifest in the form of human/nonhuman animal limits, a notion borrowed from Derrida's "limitrophy" that mark a human or nonhuman animal's state of species being (398). These characteristics, say a human animal's ability (and in turn, a nonhuman animal's inability) to speak or a bird's ability (and the human animal's inability) to fly, serve to biologically distinguish them. Identifying these limits within the text is to illuminate the characteristics that become the breeding ground for speciesism.

\section{Clothing as Civility and Servility}

Wearing garments in a public space is one such limit. Clothing, both as act and item, suggests consciousness and shame. The ability to feel conscious and shameful for wearing or not wearing clothes is deemed uniquely human, and not doing so is thought to be animalistic. Sitoy's “The Night Monkeys" and Bravo's Fetch employ this limit as a way of maintaining an easy, visual distinction between humans and nonhuman animals.

In the human world, clothing is a marker of civility. Ergo, humans, who clothe themselves, are considered civilized. Sitoy's narrative reiterates this fact through an irony where the night monkeys are clothed. On the first hour the night monkeys set out, Bea sees her parents' night monkeys: “There was Mama's monkeys, who was a great scandal to look at, bright orange all over and with a purple feather boa and lots of bracelets and dangly hoops in her ears... There was Papa's monkey, who wore a leather vest and mirror shares. ." (Sitoy 8; emphasis added). Although fantastical and serving a literary purpose to entertain the child, the passage is notable for the ironic situation of clothed nonhuman animals. It is both wondrous 
and hilarious to conceive this notion, since nonhuman animals are not considered civilized. Seeing them in human clothing contradicts the civility symbolized by it. This contradiction reinforces the fact that clothing is only, normally a human trait.

But in those few times that nonhuman animals are clothed, they wear garments or accessories that symbolize their servility to the humans who dress them. The collar Dog wears in Bravo's Fetch suggests this submission. Throughout the visual narrative, Dog wears a red collar as he runs errands for his master. Dog collars are used for "identification," "decoration," "control" and even "punishment" ("Dog Collars: Which Type is Best for Your Dog?"). It is interesting to note that the collar's functions are related to what humans do to dogs: identify them as their pet, style them according to their whims, control them to preserve order, and punish them if they misbehave. Unlike humans who can dress themselves as a means of selfexpression, the act of dressing nonhuman animals is a venue for human subjugation.

In both texts, clothing serves as a limit that defines and separates the human from the nonhuman animal on the basis of its implications about both species.

\section{Imagination as Human Hallmark}

The mind can be a viable source for limits. Lev Vygotsky defines imagination as "the basis of all creative activity" and "an important component of absolutely all aspects of cultural life, enabling artistic, scientific, and technical creation alike" (9). Both humans and nonhuman animals possess imagination. However, it is believed that the former possess a more complex form. "In this sense," Vygotsky explains, "absolutely everything around us that was created by the hand of man, the entire world of human culture... all this is the product of human imagination and of creation based on this imagination" (9-10). What differentiates humans from nonhuman animals with regard to imagination is supposedly what and how the species transforms it into.

Due to their creative control over their imagination, the young girl in Garcia's Tiger on the Wall and Rahal of Bravo's The Cat Painter become remarkable human characters. The former's ability to imagine a tiger out of a wall stain is notable given that there is no tiger-related image to associate the stain with. By herself, she is remarkable when juxtaposed to the jaded adults in her household who cannot imagine this tiger like she does. Rahal, on the other hand, elicits awe from God because of the creative and colorful fur designs he introduced.

The tiger and the cats are easily distinguished by their inability to control imagination. They are depicted without imagination insofar that they have become the product of someone else's. The tiger is nothing more than an imaginary entity. While not born out of Rahal's mind, the cats are indebted to their human painters for their colored bodies. These two nonhuman animals provide a stark contrast to the imagining humans by highlighting the latter's execution of a mind power.

Kritika Kultura 24 (2015): -055

(c) Ateneo de Manila University

<http://kritikakultura.ateneo.net> 


\section{Theory of Mind}

Another aspect of the mind where limits may be marked lie in a particular set of cognitive skills. Theory of mind, according to Lori Gruen, is the ability "to understand that another being feels, sees, and thinks, and to get a sense of what those emotions, perceptions, and thoughts might be" (13). Like imagination, cognition has been used as a mental measure of comparison between humans and nonhuman animals. With regards to theory of mind, humans are perceived as the more noteworthy species for understanding, relating and feeling sympathy and empathy. ${ }^{8}$ Theory of mind is used to discern species in Vizcarra's Ang Itim na Kuting.

In Ignacia's misunderstanding of her expectations, the young child, her owner, employs theory of mind to understand Ignacia's intentions. In the story, Ignacia attempts to impress her potential human owners by offering her services as a cat. Ignacia keeps her act even when the young girl adopts her. Still, Ignacia is unable to understand that her master wants a friend and not someone who serves her: "Ayaw ko ng yaya... Gusto ko ng kaibigang pusa 'I don't want you to be my nursemaid... I want you to be my friend" (Vizcarra 25). On the other hand, the young girl understands Ignacia to the extent that she senses that this cat is yearning for affection and acceptance. Theory of mind is then displayed by the young girl through her motherly instincts and the maternal figure she assumes. Ignacia represents the species believed to be incapable of realizing theory of mind, which differentiates her from her human master.

\section{Spoken Language}

Another more common recognizable limit is language. On the uniqueness of human language, Jason Goldman states that "language is more than a process through which meaning is attached to words or short sentences... [It is] the ability to take a finite set of elements (such as words), and using a set of rules (grammar and syntax) to create infinite [incomprehensible] combinations" ("Is language unique to humans?"). With its complex linguistic system, the human animal is taken to be more sophisticated than the nonhuman animal that relies on a gestural or simple auditory syntax.

Alfar's "Menggay's Magical Chicken" uses spoken language to distinguish the two species. In not being able to speak, the closest the chicken can do that passes as communication is its habit of arranging grains. The patterns it creates require human interpretation. When kidnapped, the chicken is branded "useless, stubborn, ugly [and] stupid" by the siokoy who could not understand the grain patterns (Alfar 
52). Language comes in two forms in this narrative: the gestural and the spoken. The nonhuman animal is attributed the former while the human animal communicates with the latter. The latter, however, is magnified as the ultimate divider of the two, where the species unable to utter that language becomes the pale antithesis to the speaking species.

Apart from flaunting awareness of the notion of species and distinguishing them, the genre's reiteration of these human/nonhuman animal limits encourages speciesism within itself. Introducing humanity and animality through these traits are not problematic per se. However, introducing humanity as a species endowed with seemingly better qualities leads to the beginning of the persistent yet sometimes unconscious discrimination toward the nonhuman animal species, where the latter functions as a foil to the former. The nonhuman animals are introduced, on the other hand, in a manner where their unique, remarkable capacities are not taken "as signs of their superiority over humans" (Taylor 211) ${ }^{9}$. As a result, this discrimination supports the enduring myth of human uniqueness; and promotes misconception of the nonhuman animal via debasing distinctions. This discrimination encourages a system of species recognition rooted in bias-particularly toward humans-and species politics; a politics driven by concrete humanist biology, which renders the features of the human species automatically outstanding.

\section{HUMAN/NONHUMAN ANIMAL REPRESENTATIONS}

This species politics is evident in the biased treatment of the human and nonhuman animal subjects in the texts. The representations of both species crystallize speciesism further by illustrating humans not only as a "better" species but also as a species whose value is greater than its nonhuman animal counterpart.

\section{The Revered Human}

A concrete example is the depiction of the human subject as revered figures of authority and exceptionality. Authority is best illustrated by depicting humans as masters. The master image is assumed by the old man in Bravo's Fetch, the human angels in The Cat Painter, and the young girl in Vizcarra's Ang Itim na Kuting. The old man reinforces his status by depending on and expecting Dog, his pet, to do things for him. The human angels exercise their authority, as imposed by God in the text, as the cats' painters by painting them according to their preferences. Despite wanting to be friends-an equal-with the cat Ignacia, the young girl in Vizcarra's book asserts her mastership through an insistence: "Ayaw ko ng yaya... Gusto ko ng 
kaibigang pusa" (Vizcarra 25). This insistence suggests her expectation of the cat's subservience to her orders. Befriending Ignacia, despite the cat's persistence to be of service to her, is symptomatic of her authoritative capability as her pet's master. Control over circumstances and others place these characters and the species they embody as no less than figures of power.

Meanwhile, exceptionality takes the form of gifted protagonists in the remaining texts. Bea of Sitoy's "The Night Monkeys" is exceptional for the human freedom to choose. This quality becomes exceptional when juxtaposed to the night monkeys' condition, who rely on humans' dreams to exist and materialize (Sitoy 13). Menggay of Alfar's "Menggay's Magical Chicken" is deemed exceptional as a model of goodness, interpreter of her chicken's grain patterns, and the lone being with magic. ${ }^{10}$ In Garcia's Tiger on the Wall, possessing imagination is what makes the young female protagonist exceptional. The skill of imagining sets her apart from the other characters due to her seeing the elusive tiger (Garcia 24). Her personal quirk lends her exclusivity since only she can experience a friendship with the nonhuman animal. Lending exceptionality to human characters is another means of attributing power to and revering humans.

\section{The Animal Less Revered}

On the other hand, the nonhuman animal subject is not held in the same light. Their species is illustrated in ways devoid of agency and exceptionality thus as creatures of lesser value. The deprivation comes from their misrepresentation.

\section{The Animal Stereotype}

One method of ill representation is the animal stereotype. It has long been employed in different media, and Sitoy's "The Night Monkeys" noticeably borrows that of the monkey's. These nonhuman animals are depicted here to be rowdy and living on spontaneity and festivity. Midway into the narrative, Bea witnesses the spectacle created by the restless monkeys at the plaza:

It was a veritable ape-fest. Big ones and little ones alike hung by their tails from the basketball goals or the branches of acacia trees. Oranges and banana peels flew through the air. The Monkeys slurped their cocktails, showed off their spangles and their silks, and screeched and shoved, and behaved like nasty First Grade schoolboys when the teacher wasn't looking... (Sitoy 10-11)

This representation maintains the tradition of depicting monkeys as a species that wreaks havoc. It is interesting to note that the monkeys are used to present the other, "animal" side of humans in this text ${ }^{11}$ and that side, if lived out, will yield chaotic consequences. Because of its perceived aggression due to their "hostile" 
and "exceptionally loud vocalizations" (Neil, "Social Structure") the monkey, as believed earlier as a fitting animal to "[allude] to what was believed to be [Filipinos'] upbringing in the jungle"12 (Herbst 151), is and has often been imagined as a stereotypical, local animal symbol of mayhem and even incivility.

\section{The Humanized Animal}

Anthropomorphism, like stereotyping, has been in vogue as a method of animal representation. "Humanizing" here, however, is defined as mild anthropomorphism, where only few human features are incorporated into the nonhuman animal's representation.

All six narratives evidently humanize their animals (e.g., attribution of human language) at least in one aspect albeit Bravo's Fetch and Vizcarra's Ang Itim na Kuting are notable for humanizing nonhuman animals in subtler ways. In the former, Dog runs errands almost like a human. At one point, when he fetches his old master a banduria, the visual narrative depicts Dog returning to his master and presenting the item with his upturned paws. Humanizing takes place here in Dog's reenactment of a human action.

Ignacia, the black kitten in Ang Itim na Kuting, shares a similar case with Dog. In the part where she meets the young girl, her future master, at the gate, Ignacia is seen with large, lashed eyes and a toothy smile. The facial expression however is not "catly" but more humanlike. The attribution of eyelashes and a human grin, for instance, are not realistic. Cats do not have eyelashes ("Anatomy and Physiology") and also cannot smile like humans for their grin consists of "squinting" (Newkirk, "Reading Your Cat's Eyes") rather than flashing teeth. Ignacia's humanization is in the form of the visual reconstruction of her facial anatomy.

\section{The Objectified Animal}

In the instance when the portrait of the nonhuman animal is less played with, it becomes a "theorem, something seen and not seeing", meaning objectified to the point of silence (Derrida 383). The chicken and the cats in Alfar's "Menggay's Magical Chicken" and Bravo's The Cat Painter are depicted as objects to be looked at not as creatures that see.

A fascinated tone colors the description of Menggay's chicken and the cats in the angels' painting heaven. To introduce the chicken and its unusual habit of arranging grains, the narrator depicts it with an objective tone albeit with notable wonder: "it was an odd-looking chicken ... [that] would leave most of the grain where it fell. But it would pick up several grains one by one in its beak, then put them down carefully in different spots" (Alfar 48). The cats' visual representations evoke admiration as a work of human art (Bravo 26). This tone enhances these animals' quality as passive objects to be scrutinized and manipulated. 


\section{THE “DEFLATED” ANIMAL}

But manipulation does not only occur in the nonhuman animal's objectification. Deflation, which here means the toning down of certain animalistic traits, is also a method of nonhuman animal representation.

Garcia's tiger emulates an easily domesticated cat more than the ferocious, commanding feline. It waits on the young girl, "weave[s] in and out of [her] legs," (5) "springs on her bed" (9) and even licks her face (9-10). The tiger depicted is filled with affection and readiness to be kind to the human girl. Manipulative deflation happens in the obvious and conscious, considering the genre's audience, effort to dumb down the animal. This effort is evident in the text's defiance of the real-life tiger's ferocious social behavior.

The significance of value hovers over the preceding discussion. In fact, speciesism is founded on matters of value. Clearly, human/nonhuman animal representations in the narratives are informed by notions of species' "inherent" and "intrinsic" values, which respectively mean "hav[ing] value in their own right" and finding value in their "individual experiences" (Regan 18-19). The treatment of both subjects is symptomatic of a "Greater Value Assumption" which is defined by Tony Milligan as the belief where "humans are of more value than anything else" (226). This greater value assumption manifests in the inversely proportional values of these species.

The expansion of the human subject and the reduction of the nonhuman animal actualize this imbalance. Humans are treated as a more "valuable" species for the authority and exceptionality supposedly granted to them. ${ }^{13}$ There is intrinsic value in authority because of the string of privileges that comes with it. The human masters-the old man, human angels and the young girl-enjoy the privileges of ownership and other species' service. In the case of exceptionality, intrinsic value lies in the endless possibilities that humans are capable of living out. Bea's freedom of choice, Menggay's "magic," and the young girl's imagination enable the accomplishment of tasks and dreams of a larger scale. The total intrinsic value of humans relies on their ability to transform superiority into influence and control. Humans and their inherent value then are "expanded" in the sense that they are magnified, stretched, made larger-than-life by their experiential advantages. This creates the illusion-illusion because reality calls for the recognition of both sides of the binary as important ends-in-themselves - that whatever juxtaposed to them is of a much lesser value (qtd. in Tester 13).

This illusion degrades both the intrinsic and inherent values of the narratives' nonhuman animals. What John Berger coins as the "reduction of the animal" operates in the general treatment of this subject (13). Nonhuman animals are reduced by their one-dimensional representations. In stereotyping, the method confines the monkey within certain parameters. These parameters bind the monkey 
to a certain image, an image informed by society's myths and cultural beliefs and not so much about scientific realities about the monkey. This leads in turn to the propagation of the monkey image as simply an animal of mischief.

In humanizing the nonhuman animal character, the method removes its uniqueness and state of being. As acknowledged earlier, anthropomorphism in children's literature is conducive to children's imagination and cognitive development. However, there is also the possibility of personification being used to forward speciesism. Humanization is not speciesism per se; rather, it is a vehicle that advances it depending on how distorted and uninspiringly humanistic the portrayals become. In the study "Do Cavies Talk? The Effect of Anthropomorphic Picture Books on Children's Knowledge about Animals," Patricia Ganea and her team have explored how anthropomorphism in children's books affects the way children learn and perceive the animal. Three, four and five-year old children who lived in urban settings have participated in the study, indulging in both fantastical texts and language of humanized animals and factual materials. The research has shown that this method of depiction "may not only lead to less learning but also influence children's conceptual knowledge of animals" (Ganea et. al, "Do Cavies Talk?"). ${ }^{14}$ Fashioning animals in humans' image then is proven to be reductive since doing so detaches the literary animal farther from its "animal-ness."

Objectification reduces the nonhuman animal as non-responsive creatures to be silenced and made absent. Their incapability to participate in the text's events is denying them their active presence, thus invalidating their value. In deflation, reduction comes in the oversimplification of the nonhuman animal's depiction. This oversimplification downplays the complex and actual social behaviors of the nonhuman animal represented.

While it is understandable for the genre to allow simple representations to assist the child's understanding of the narrative and nonhuman animal, it should also be noted that animals still are agencies in themselves in the same way female characters in today's children's books have been realized as such insofar as they have been rewritten as entities sans their culturally attributed domesticity and passiveness. The nonhuman animal deserves more accurate imagery. As seen in these four methods, the nonhuman animal species "has lost its general qualities, all of them retaining only their distinct capacities" (qtd. in Berger 12). The distinct capacities too are conventional and superficial. While humans are held in high regard for their influence and control, the nonhuman animal subject is treated not with revering attention but with indifference: an indifference toward achieving dignified representations due to their believed inferiority. This indifference exhibits itself in how the narratives gloss over this subject, and dwells in the inaccurate ambiguities of animality. The one-dimensional representations attest to the lesser amount of value attributed almost uninspiringly to the species. The inherent value of the nonhuman animal is penned to rest on and return to its literary nature as tool and subservient species, more accurately as a means serving human ends.

Kritika Kultura 24 (2015): -059 


\section{HUMAN/NONHUMAN ANIMAL RELATIONSHIPS}

Speciesism still flourishes elsewhere. Apart from an underlying "Greater Value Assumption", the narratives also contain a "Sole Value Assumption" where "humans are [regarded] the only bearers of intrinsic [and inherent] value" (Milligan 226). This particular assumption manifests itself in the narratives' suggestion that humans are the most valuable species - so valuable that another species' lesser value merely serves to establish humans' paramount value. This suggestion is actualized by the narratives' interspecies relationships.

\section{Superior Human, Inferior Nonhuman Animal}

Becky Bravo's Fetch and The Cat Painter showcases a type of interspecies relationship founded on hierarchy. Fetch illustrates this hierarchal relationship through the master-servant bond that the old man and Dog share. However, the most significant nuance that best suggests the relationship is Dog's bilingual address to his master. Dog addresses the old man as either "master" or "Panginoon" (Bravo 7). While "master" hints at superiority, "Panginoon"-a Filipino term that may mean god-hints at the supreme agency attributed to this human revered as god.

In The Cat Painter, the human angels are the masters while the cats the servants. While Dog accomplishes concrete tasks as his service, the cats' silence and subservience to the angels' creative whims are their services. Interestingly, despite their mastership, the human angels are also seen rendering service to God through cat painting. What is even more interesting is the fact that God is implied to be a gargantuan human in the visual narrative (22). The portrait of humans serving humans gestures toward the speciesist belief that only the human species is worth submitting to. Dog's service, the cats' lack of agency and their silent submission cement their inferiority.

\section{The Human-Dependent Nonhuman Animal}

The nonhuman animal's inferiority may also be veiled under a quality of dependency. Humans are who the species depended upon. Sitoy's "The Night Monkeys" and Garcia's Tiger on the Wall contain a type of interspecies relationship mirroring this situation.

Bea and the other humans do not depend on the night monkeys for anything. On the contrary, the night monkeys are dependent on these humans for a major, immaterial need: their very existence. The night monkeys' role as the unfulfilled ambitions of humans suggests that if not for these human dreams, they will not exist. Bea's case attests to this important fact where her determination to pursue her dreams and whims leads to the non-existence of her night monkey (Sitoy 14). 
The tiger faces the same dilemma where it also depends on humans for existence. While the night monkeys are dependent on dreams, the tiger is dependent on human, the child's, imagination. Without it, the tiger disappears and is instead visualized as an "ink stain", "bike grease", "garden soil", "car fumes", and simply "a blot on the wall" (Garcia 18-22). On the other hand, humans can live without or outgrow seeing this tiger. Humans' independent existence here makes them seemingly the most superior.

\section{Out of Human Interests}

But Vizcarra's Ang Itim na Kuting and Alfar's “Menggay's Magical Chicken” make humans and nonhuman animals appear equally significant. Ignacia is a cat of function to the young girl who adopts her. The chicken arranges grains into telltale patterns for Menggay to interpret. However, both relationships, no matter how equal their values seemed to be, are founded on human interest. This type of relationship suggests that everything will always be subscribed to the more valuable species and their needs.

In Vizcarra's narrative, the young girl's desire to befriend Ignacia stems from a personal interest of gaining friends. Based on her insistence, gaining friendship presents itself as a human need more than an animal need (Vizcarra 25). The desire to have Ignacia as a friend instead of a nanny may explain why the young girl might have adopted the cat in the first place-that is, she sees a potential friend in this animal.

Human interest in Alfar's text manifests as a desire to solve personal problems. Fueled by the belief that the chicken's patterns may offer solutions, the village people visits Menggay and her chicken. Menggay, knowing that interpreting the patterns will be beneficial to them, maintains a relationship with her pet: "Menggay would stare at the patterns the chickens made, and divine important messages out of them for her family and neighbors" (Alfar 48). These human desires then become the foundation for these narratives' cross-species relationships.

"Sole Value Assumption" is characteristically speciesist for assuming that human's intrinsic and inherent values not only dwarf but also defeat the intrinsic and inherent values of the nonhuman animal (Milligan 226). The narratives translate this assumption through the recurring suggestion that humans are the crux of interspecies relationships. In relationships founded on hierarchy, humans are made masters to imply their being at the apex of species hierarchy. In relationships founded on dependency, humans are exaggerated to be species of power and possibilities. In relationships founded on human interest, interspecies interaction is fueled by human needs rather than a genuine concern for the nonhuman animal.

These relationships portray humans as a cause, as the species whose existence is necessary for others' significance. Nonhuman animals are made to seem reliant on these humans; their inferiority later on evolves into a striking insignificance that 
underlines humans' superlative agency. When humans do approach the nonhuman animal, the latter is used to serve greater, human purposes thus materializing the speciesist assumption that humans' inherent value trumps and may override other species' inherent value for simply-according to speciesist logic-"(hu)man is godlike, animals thinglike" (Coetzee 23).

Such deep-seated speciesism in the mentioned elements of the text impacts the literary depiction of the human/nonhuman animal in ways that distort the binary's reality of equal significance. Distortion happens when speciesism inspires a "distanced" approach to animality, where approaching the subject eventually came to mean disinterestedly looking at and effectively estranging the nonhuman animal subjects. Due to its speciesist nature, these human/nonhuman animal narratives tend to wallow in their human biases-as evidenced by the limits, representations, and relationships-which successfully distance them from the animality they wish to approach in the first place.

In distancing too, the narratives find themselves in a self-made irony: approaching animality without the knowledge of the impossibility to do so. The impossibility stems from the distance created by what Derrida would call "self-interested misrecognition" (qtd. in Wolfe, "Introduction: Exposures" 29). This may mean that a distanced approach to animality is out of the unconscious practice of preserving such prejudiced notions and illustrations to reinforce human superiority. Therefore, self-interested misrecognition is from the conscious effort to pursue a speciesist self-interest, the preservation of humans' supreme agency within the realm of the text. Practicing this self-interested misrecognition through a distanced approach prevents the narratives from achieving genuine portraits of animality because they prove to be concerned with maintaining hyperbolic images of humanity. Staying speciesist in nature yields to detached and uninspired depictions of nonhuman animals. In turn, these depictions may promote misleading, speciesist messages about their significance and moral status-a clear challenge to Philippine children's literature, a genre that intends to familiarize children with immediate truths.

\section{THE CHALLENGES OF STAYING SPECIESIST}

The consequences brought by a distanced approach to animality are problematic in themselves. However, the very existence of these speciesist narratives poses further challenges to the genre. Considering its social functions and influence as an educational tool, Philippine children's literature remains questionable for what some of its speciesist narratives present as natural, proper, and human in relation to the nonhuman animal. 


\section{Problematizing the Natural}

In his critical work The Child's Concept of Story (1978), Arthur Applebee stresses the capability of children's literature-as with any literature - to portray or at least bear semblance to the reality outside the text: "stories [children] hear help them to acquire expectations about what the world is like ... without the distracting pressure of separating the real from the make-believe" (qtd. in Pinsent 22).

Speciesism in the genre leads to the biased fabrication of one kind of reality, that of the human/nonhuman animal's. A speciesist, fabricated reality is the skewed reality of a world with a natural tendency to favor humanity. This skewedness comes from the false notion that humans are the only species of value and agency.

As presented by the earlier analyses, humans are written in such a way that they look naturally significant and exemplary through recurring images of their superiority. Humanity is made to own agency, and agency is made to seem exclusive to them. Such extreme humanism veils the binary's equality. The naturalness is justified by speciesist claims, which make it prejudiced and dubious in nature. Given the practice of a self-interested misrecognition, it may be said that these speciesist versions of reality are more concerned with conserving the mirage of human greatness rather than reminding readers of species equality.

Perhaps, this tendency is explained by humans' desire-with these narratives serving as its media-to transcend their fate as creatures equal to nonhuman animals. Stephen Clark posits that:

[humans] are ashamed of the fact that [they] are merely one equal part of something which far transcends [them]... [They] wish to create a world where [they] are masters, and where ... reminders of [their] real defencelessness [original spelling] as wild nature are kept firmly in their place (qtd. in Tester 11).

Clark suggests that the only natural truth in this manipulated reality is that humans have a natural tendency to acquire significance and agency. The belief that humans are above all else is simply a fact fabricated out of a human tendency, a fact that speciesist children's narratives continue to promote, and that children might think true. The chosen texts cater to children from ages seven to 12, suggesting that they cater to a certain set of children who have "start[ed] to develop a sense of equality" or in this sense, inequality (Norton 35).

A sense of species equality means acknowledging the species' relevance in not just the literary but also the ecological scheme of things. While the very concept of ecological niches reiterates that ecological objects in a natural space are interrelated through interactions such as competition and other types of relationships involving necessary power dynamics, equal significance among species is a construct achieved when nonhuman animals are depicted and realized 
apart from their dependent relation to humans (Patten and Auble 893). The literary nonhuman animal, then, is equally significant in that its independent role in nature and adaptive or survival skills in its real-life ecological space are truths relevant to the construction of its fiction. To depict the nonhuman animal as ultimately reliant on the human animal is to maintain the speciesist assumption of the latter being the bearer of other species' purpose. Unless there is a renewed approach to nonhuman animal species, the possibility where readers comprehend these implicit speciesist notions of equality will continue to exist.

\section{(Im) Proper Marginalization}

Children's literature is believed to be able to impart cultural beliefs to a child. This informative process is particularly called "socialization," which David Shaffer defines as a "process by which children acquire beliefs, values and behaviors deemed significant and appropriate by the older members of their society" (qtd. in Norton 28). Shaffer implies here that the genre teaches only proper behavior to its readers.

With socialization also come lessons of categorization. Through the manner of literary observation, children may learn socialization specific to their immediate cultural environment: "observation of others teaches children the responses, behaviors, and beliefs considered appropriate within their culture. Children learn how to act and what to believe by imitating adults and peers" (Norton 33). Literature, therefore, can succeed in providing their child readers the tools needed to develop their social developmental skills.

The problem with speciesism is that it disguises an improper practice as proper. Speciesist narratives normalize marginalization of nonhuman animals and make it seem morally acceptable. Marginalizing, as humans know, is oppressive hence is far from proper. Humanity has been striving hard to de-marginalize certain societal sectors thus showing their awareness of its negative effect. Nonhuman animals are believed to be lesser species, making them supposedly deserving of inferiority. In speciesist narratives, marginalizing nonhuman animals is subtly depicted as a tolerable practice. Because it does not jeopardize human interests and superiority, marginalizing nonhumans is suggested as acceptable, appropriate societal behavior to be imitated by humans.

Lori Gruen stresses, "much of what is thought to be natural behavior is in fact, conventional behavior, behavior that [humans] can, and should, hold up to normative scrutiny" (52). Eugene Evasco argues that the genre is capable of not only reflecting culture but also criticizing it: "nababale-wala ang kakayahan nitong tumalakay ng seryosong paksa o pumuna gaya ng mga panitikang pangmatanda" (emphasis added, 48)15. These speciesist narratives point to the current limitation of Philippine children's literature to criticize an improper cultural attitude with regard to nonhuman animals as it unconsciously promotes it to the child reader. 


\section{What it Means to be Human}

Teaching children about the world and local propriety is an endeavor that subscribes to the bigger goal of teaching them what it means to be good humans. The phrase "good humans" means being able to possess the capability to uphold morality and to connect worldly knowledge with learned propriety. In line with this belief, Arlene Pillar maintains, “Children's literature holds great potential for fostering moral growth" (148).

While teaching good morals to children, speciesist narratives also promote a flawed sense of what it means to be human, let alone being good ones to nonhuman animals. If the knowledge connected with propriety is that of a fabricated reality; and the propriety associated with that reality is the toleration of nonhuman animal marginalization, the narratives are teaching children to become humans confident in exercising their authority over other species. This authority is dressed as a human privilege. Speciesist narratives endorse humanness to be the acceptance and practice of the "ethical" privilege to subordinate nonhuman species.

As argued by this paper, oppressing nonhuman animals is a bias driven by warped species politics. With this, the genre risks teaching children that being human may mean and entails unethically subjugating nonhuman animals. In Christie Routel's study on "The Impact of Children's Literature and Discussion on Attitudes Toward Disability" where it employed a mixed-methods approach and randomly assigned twenty-one fifth grade students to read the prescribed literature, results have indicated:

that it is possible for carefully selected literature and guided discussion to have an ameliorating effect on negative attitudes[,] and create a window of opportunity for further change... The effectiveness of the use of literature implies a potential need to alter classroom practices and teacher preparation to take advantage of the chance to change children's negative attitudes toward people with disabilities. (65; emphasis added)

Routel's study concretely presents the capacity of literature to influence attitudes, both positively and negatively. With speciesist narratives, the risk of influence poses a clear danger: considering the chosen texts are for children from ages seven to 12-at ages where they are scientifically proven to grasp the concepts of self-worth and self-assurance after "develop[ing] a set of feelings about themselves ... [and] consider[ing] themselves ' $\mathrm{I}$ "' at age three-it is safe to presume that these texts may be influential in reminding their readers of their worth not only as an individual, but also as a superior human child (Norton 27) .

At the least, the intent to bridge the concept of animality to the child reader through methods mentioned is modest and noble. For children to relate and later empathize with stranger species, picture books such as these are proven to help 
forward not only simple notions of the nonhuman animal, but also creativity among them. At most, however, books symptomatic of speciesism are detrimental to understanding the position of the nonhuman animal as an equal-again, meaning equally deserving of attention and the consideration as ends-in-themselves. These texts are items of knowledge children can easily consult when craving fast answers to questions of being ("What is the [nonhuman] animal?"), role ("What do they do in this world?"), and relationship ("What are they to us? What are we to them?").

Earlier arguments about Philippine children's literature being reliable in introducing concepts to children appear flimsy vis-à-vis its treatment and introduction of animality. The genre's speciesist tendencies have misappropriated animality and constructed the nonhuman animal into a definite "other," the "absolute other" that is "wholly other, more other than any other" (Derrida 380). The conscious othering of the nonhuman animal is unique. Not only does the realm of animality allow the nonhuman animal to be othered by scientific limitations, that means to say the inability to access what the nonhuman animal perhaps thinks and feels, but the nonhuman animal here is othered further by intentional, selfinterested means. The process of othering happens in the indulgent empowerment of the human, where the marginalization of the nonhuman animal becomes a consequence. As a result, the child reader is led to false truths about animality and even the nature of their very humanity.

While it distances the genre from animality, speciesism also distances the child reader from the topic the genre purports to bring closer to him/her. The challenge to the genre then is deviating from these inclinations and leaning toward informed portraits of both species, informed in the sense that they display thoughtful engagement with both human/nonhuman animal subjects-portraits that aid in the genuine distinction of humanity and animality, and the bridging of children to the nonhuman animals they are strangers to.

Speciesism has displayed itself as a deceptive philosophy that subverts the already unpopular reality of the equal significance between the human/nonhuman animal species. This subversion has created an even wider distance between the two-a distance that has displaced and pushed the nonhuman animal to the margins of humanity, its plight naturalized by speciesist ignorance. The nonhuman animal remains at the edges, misrepresented until approached, and silenced until granted literary voice.

Or perhaps, the nonhuman animal has already spoken: its deafening muteness being the voice that shatters its very silence. All it needs now is a multitude that will listen. 


\section{Notes}

1. In his famous address to the 1997 Cerisy conference, "The Animal That Therefore I Am (More to Follow)," Jacques Derrida reflects on the significance of considering the experience of the nonhuman animal, its experience as a being that sees ("can we say that the animal has been looking at us?"), to the question of approaching animality and its "alterity" (372-380).

2. In his essay "The Ethics for Rest of Nature," philosopher Paul Taylor proposes a biocentric outlook and attitude that encompasses (or more accurately, focuses) wild plants and creatures previously ignored in the scheme and popular discourse of animal rights and equality.

3. Tony Milligan provides a refined definition of Richard Ryder's and Peter Singer's speciesism which the latter describes to be "a prejudice or attitude of bias in favour of the interests of members of one's own species and against those of members of other species" (qtd. in Milligan 224). Milligan, in finding the term "species-neutral," defines speciesism in the light of anthropocentrism from which it has become associated with (223).

4. Although these words are believed to carry overlapping meanings, 'human' and 'person' may still be defined separately. Lori Gruen takes 'human' to scientifically mean 'a member of the species Homo sapiens'; and 'person' to be an entity with "value or worth ... [and] "rights" and who is the subject of ethical duties and obligations" (56-57).

5. In the essay "The Child's Need for Magic," Bruno Bettelheim has argued at one point that children's affinity with animals is largely influenced by their animist thinking. In animism, not only is there a nonexistence of species categories but also a deep reverence for other agents in nature, which makes interspecies interaction free of species biases (130).

6. "Most of us are humanists to the core" - this was Cary Wolfe's verdict on cultural studies in his belief that it is speciesist in nature for assuming that the object of study is "always already human" (1). Cultural studies remain humanistic as it attends to matters involving only the human species even when its critics claim that their work "is an epistemological break with humanism itself" (1). The lack of discourse on the nonhuman animal in Philippine cultural studies verifies Wolfe's contention.

7. For a sample, radical proposition of tackling animality, see Derrida's limitrophy hypothesis (398-399).

8. The abilities to relate with others are considered not only impressive but also beneficial. A study done by Keith Oatley, Raymond Mar and Jordan Peterson is one of the earlier to have related fiction with empathy and suggested that the former's extensive influence may yield positive micro and macro consequences (407-428).

9. In the same essay, Taylor criticizes the basis of speciesism and human superiority: "In what sense are humans alleged to be superior to other animals? We are different 
from them in having certain capacities that they lack. But why should these capacities be a mark of superiority? From what point of view are they judged to be signs of superiority and what sense of superiority is meant? After all, various nonhuman species have capacities that humans lack. There $s$ the speed of a cheetah, the vision of an eagle, the agility of a monkey" (211).

10. The chicken is first believed to be the magical creature in the text, and this fact entices the siokoy, the antagonist, to abduct it. After the siokoy mistakes the chicken as magical, the townspeople are convinced that the magic lies in Menggay alone: "we townsfolk knew that you were the only one who could read its messages... [we] don't think the chicken has magic, Menggay; I think you do" (Alfar 53).

11. In the narrative, the night monkeys embody the identities and ambitions humans have failed to live out. Hence, they serve as the other 'face' of the humans in the world of Bea, the protagonist.

12. The local monkey stereotype may date back to when Filipinos themselves are tagged as "brown monkeys" by the Americans. Monkeys were and still are used as a contrast to or measure of civility.

13. See Derrida 383-387 for a deconstructive reading of the Genesis' creation, one of the oldest literary accounts that have established the 'naturalness' of human superiority.

14. Published in the journal Frontiers in Psychology, Ganea's study displays the effects of anthropomorphizing animals in picture books on the child's conception of the real-life nonhuman animal, and problematizes the literary method as a manner of familiarizing children - particularly preschoolers in this study - with the environment and its other nonhuman inhabitants. The research has found two notable phenomena: the eldest participants exhibit higher tendencies of attributing "human physical behaviors and emotions when asked about real animals," (Ganea et al.) and children do learn more about animals through factual books with realistic pictures. While it warranted criticism for seemingly devaluing picture books, the study is firm in its first and foremost main objective to suggest an alternative to picture books if parents and teachers wish to educate children about animality: "if we want children to learn new things about animals, we need to expose them to stories that present the animals and their environments in a biologically realistically manner" (Ganea et al.).

${ }^{15}$ In English: "Because of the genre's seemingly simplistic nature, the capability of children's literature to tackle and criticize mature themes and topics is often ignored or underrated." 


\section{Works Cited}

Alfar, Nikki. “Menggay's Magical Chicken." The Night Monkeys: More Palanca Prize Winners for Children. Makati City: Tahanan, 2008. 48-53. Print.

"Nikki Alfar." Flipside Publishing Services, Inc. Flipside Publishing. 2012. Web. 8 Feb. 2015.

"Anatomy and Physiology." UC Davis Veterinary Medicine. Regents of the U of California, Davis, n.d. Web. 5 June 2013.

Backes, Laura. “Understanding Children's Book Genres." Right-writing.com. n.d. Web. 7 Dec. 2014.

Bekoff, Marc, ed. Encyclopedia of Human-Animal Relationships: A Global Exploration of our Connections with Animals. Connecticut: Greenwood, 2007. Print.

Berger, John. "Why Look at Animals?" About Looking. New York: Vintage, 1992. 3-28. Print.

Bettelheim, Bruno. “The Child's Need for Magic." The Uses of Enchantment: The Meaning and Importance of Fairy Tales. New York: Random House, 1975. Print.

Bravo, Becky. The Cat Painter. Quezon City: Adarna, 2006. Print.

--. Fetch. Manila: Lampara, 2009. Print.

Burke, Carolyn and Joby Copenhaver. "Animals as People in Children's Literature." Language Arts 81.3 (2004). 205-13. Print.

“Children's Literature: Cats." Encyclopedia of Human-Animal Relationships: A Global Exploration of Our Connections with Animals. 2007. Print.

"Children: The Appeal of Animals to Children." Encyclopedia of Human-Animal Relationships: A Global Exploration of Our Connections with Animals. 2007. Print.

Coetzee, J.M. "The Philosophers and the Animals." The Lives of Animals. New Jersey: Princeton UP, 2001. 15-45. Print.

Cohen, Ed. "Human Tendencies." E-misferica 10:1 (2013). n.pag. Web. 14 Mar. 2013.

Derrida, Jacques. "The Animal That Therefore I Am (More to Follow)." Trans. David Wills. Critical Inquiry 28.2 (2002): 369-418. JSTOR. Web. 23 Sept. 2012.

"Dog Collars: Which Type is Best for Your Dog?" The Humane Society of the United States, 2 Nov. 2012. Web. 20 May 2013.

Eugenio, Damiana. "Philippine Folktales: An Introduction." Asian Folklore Studies 44. 1985. 155-77. Nanzan Institute for Religion and Culture. Web. 26 Apr. 2014.

Evasco, Eugene. "Ang Pilyo Bilang Subersibo: Himagsikan sa Panitikang Bayan at Pangkabataan." Diliman Review 46.1 (1998): 48-55. Print.

Ganea, Patricia, et al. "Do Cavies Talk? The Effect of Anthropomorphic Picture Books on Children's Knowledge about Animals." Frontiers in Psychology. 5:283 (2014): n. pag. Web. 15 Nov. 2014.

Garcia, Annette Flores. The Tiger on the Wall. Quezon City: Adarna, 2004. Print.

Goldman, Jason. "Is Language Unique to Humans?" BBC Future. $B B C, 17$ Oct. 2012. Web. 17 Feb. 2013.

Gruen, Lori. Ethics and Animals: An Introduction. Cambridge: Cambridge UP, 2011. Print.

Kritika Kultura 24 (2015): -059 
Herbst, Philip. "Monkeys." The Color of Words: an Encyclopaedic Dictionary of Ethnic Bias in the United States. Maine: Intercultural P, 1997. 151-52. Print.

"Lakambini Sitoy." New York Review Books. NYREV, Inc. 2014. Web. 8 Feb. 2015.

Milligan, Tony. "Speciesism as a Variety of Anthropocentrism." Anthropocentrism: Humans, Animals, Environments. Ed. Rob Boddice. Leiden: Koninklijke Brill NV, 2011. 223-43. Print.

Newkirk, Ingrid. "Reading Your Cat's Eyes." PETA Prime: Celebrating Kind Choices. People for the Ethical Treatment of Animals, 2009. Web. 31 Jan. 2013.

The Night Monkeys: More Palanca Prize Winners for Children. Makati City: Tahanan Books, 2006. Print.

O’ Neill. Dennis. "Social Structure." Primate Behavior: A Survey of Non-Human Primate Behavior Patterns. Palomar College, 2012. Web. 5 June 2013.

Norton, Donna E. Through the Eyes of a Child: An Introduction to Children's Literature. $4^{\text {th }}$ ed. New Jersey: Prentice-Hall. 1995. Print.

Oatley, Keith et al. "Exploring the Link between Reading Fiction and Empathy: Ruling Out Individual Differences and Examining Outcomes." Communications 34.4 (2009): 407-28. The Mar Lab. Web. 13 Mar. 2013.

Patten, Bernard and Gregory Auble. "System Theory of the Ecological Niche." The American Naturalist. 117.6. (1980) 893-922. JSTOR. Web. 7 Dec. 2014.

Pillar, Arlene. "Using Children's Literature to Foster Moral Development." The Reading Teacher 33.2. (1979): 148-151. JSTOR. Web. 13 Mar. 2013.

Pinsent, Pat. "Chapter 2: Children and Literature." Children's Literature and the Politics of Equality. London: David Fulton, 1997. 19-37. Print.

Regan, Tom. "The Case for Animal Rights." The Animal Ethics Reader. Eds. Susan Armstrong and Richard G. Botzler. London: Routledge, 2003. 17-24. Print.

Rivera, Michelle. "Teaching Kids Kindness to Animals." The Examiner. Clarity Digital Group LLC, 2010. Web. 14 Nov. 2012.

Routel, Christie. "The Impact of Children's Literature and Discussion on Attitudes Toward Disability." Master's Theses and Doctoral Dissertations, 245 (2009): i-95. Digital Commons@EMU. Web.14 Sept. 2014.

Sitoy, Lakambini. “The Night Monkeys." The Night Monkeys: More Palanca Prize Winners for Children. Makati City: Tahanan, 2008. 7-16. Print.

Taylor, Paul. "The Ethics of Respect for Nature." Umweltethik. 1981. Web. 1 Sept. 2014.

Tester, Keith. "Chapter 1: The Claims of a Dog." Animals and Society: The Humanity of Animal Rights. London: Routledge, 1991. 1-16. Print.

Vizcarra, Natasha. Ang Itim na Kuting. Quezon City: Adarna, 1996. Print.

Vygotsky, Lev Semenovich. "Imagination and Creativity in Childhood." Journal of Russian and East European Psychology. 42.1 (2004): 7-97. XMCA Discussion Forum. Web. 15 May 2013.

Webb, Stephen. "Thinking About Pets." On God and Dogs: A Christian Theology of Compassion for Animals. New York: Oxford UP, 1998. 68-107. Print.

Wolfe, Cary. Introduction. Animal Rites: American Culture, the Discourse of Species, and Posthumanist Theory. Chicago: U of Chicago P, 2003. 1-17. Print. 
--.. "Introduction: Exposures." Philosophy and Animal Life. New York: Columbia UP, 2008. 1-41. Print. 